\title{
COVID-19 infection rate among tertiary referral center otorhinolaryngology healthcare workers
}

\author{
Kasper Møller Boje Rasmussen ${ }^{1}\left[\begin{array}{c}0 \\ \text { Peter Anders Andersen }\end{array}{ }^{1} \cdot\right.$ Hani Ibrahim Channir $^{1} \cdot$ Kasper Aanæs $^{1,3}$. \\ Jenny Dahl Knudsen ${ }^{2} \cdot$ Nikolai Søren Kirkeby $^{2} \cdot$ Mads Klokker $^{1,3} \cdot$ Christian von Buchwald $^{1,3} \cdot$ Per Cayé-Thomasen ${ }^{1,3}$. \\ Ramon Gordon Jensen ${ }^{1,3}$
}

Received: 28 September 2020 / Accepted: 7 January 2021 / Published online: 5 February 2021

(c) The Author(s), under exclusive licence to Springer-Verlag GmbH, DE part of Springer Nature 2021

\begin{abstract}
Importance Otorhinolaryngology is considered one of the medical specialties with a high risk for exposure to corona disease 2019 (COVID-19). Uncontrolled transmission in a hospital department poses a risk to both healthcare workers (HCWs) and patients.

Objective To monitor SARS-CoV-2 incidence, transmission, and antibody development among HCWs to identify high risk procedures, pathways, and work areas within the department.

Methods Prospective cohort study of HCWs using repetitive oro- and nasopharygeal swab samples, antibody tests, and self-reported symptoms questionnaires at a tertiary referral center in Copenhagen, Denmark.

Results 347/361 (96\%) HCWs participated. Seven (1.9\%) were positive on swab tests and none had symptoms. Fifteen (4.2\%) developed antibodies. Only one case of potential transmission between HCWs was identified. Infection rates were low and no procedures or areas within the department were identified as exposing HCWs to a higher risk.

Conclusions and relevance Adherence to the surveillance program was high. The low incidence among HCW during the first wave of the COVID-19 pandemic may reflect local transmission and infection control precautions, as well as a low infectious burden in the Danish society.
\end{abstract}

Keywords Protective measures · SARS-CoV-2 $\cdot$ Otorhinolaryngology $\cdot$ COVID-19 $\cdot$ Coronavirus $\cdot$ Healthcare worker

\section{Introduction}

The acute respiratory syndrome coronavirus 2 (SARSCoV-2) has to date infected 11.8 million people worldwide with coronavirus disease 2019 (COVID-19), causing a fatality rate of approximately $4.6 \%$ (July 2020) $[1,2]$. In Denmark, the first patient tested positive for SARS-CoV-2 on February 27, 2020 [3]. By the end of June 2020, 765,000 persons or approximately $8 \%$ of the total Danish population,

Kasper Møller Boje Rasmussen

kasper.moeller.boje.rasmussen@ regionh.dk

1 Department of Otorhinolaryngology, Head and Neck Surgery and Audiology, Rigshospitalet, University Hospital of Copenhagen, Copenhagen, Denmark

2 Department of Microbiology, Rigshospitalet, University Hospital of Copenhagen, Copenhagen, Denmark

3 Faculty of Health and Medical Sciences, University of Copenhagen, Copenhagen, Denmark i.e., 5.8 mill inhabitants, were tested at least once, resulting in 12,615 confirmed cases of SARS-CoV-2 infection. In total, 603 patients have died from being infected by COVID19 , leading to total of 104 confirmed COVID-19 deaths per one million individuals and a mortality rate of $4.8 \%$ [4].

COVID-19 patients who experienced any symptoms, including cough, fever, difficulty breathing, muscular pain, and nasal congestion were by March 11, 2020 advised to stay at home with the aim of avoiding transmission of the virus infection and only contact the healthcare system in emergency situations or in case of aggravated COVID-19 infection. However, people with symptoms of acute complications from the upper airways were allowed contact to an ear, nose, throat (ENT) department, as were cases of trauma or symptoms potentially related to head and neck cancer.

SARS-CoV-2 resides in the airways and often primarily in the upper airways, with the highest viral load in the nasal cavity [5]. Human transmission of SARS-CoV-2 is most likely through direct contact and partly by aerosol 
transmission. SARS-CoV-2 remains viable on plastic surfaces for up to $72 \mathrm{~h}$ with a half life of $6.8 \mathrm{~h}$ [6]. Mean incubation time is 5.2 days, with $95 \%$ of the distribution at 12.5 days [7]. Xiang et al. reported that seroconversion of specific IgG and IgM already happens four days after first symptoms onset [8]. Virus is present in the oropharynx and nasopharynx the first week after symptom onset with a subsequent decline, but viral RNA has been detected up to 25 days after [9].

COVID-19 has a broad spectrum of clinical presentations from asymptomatic to complicated pneumonias and multiorgan failure. Studies have shown that $2 / 3$ of patients with SARS-CoV-2 will present with symptoms from the upper airways [10]. Large scale population testing in Iceland has indicated that $57 \%$ of individuals carrying SARS-CoV-2 are symptomatic [11]. Other studies have suggested that asymptomatic patients are able to transmit disease [12]. With a concurrent lack of personal protection in a department with a high risk of SARS-CoV-2 exposure, it is highly relevant to identify infected patients and healthcare workers (i.e., HCWs) at an early stage, in order to prevent a COVID-19 outbreak within the department.

ENT specialists perform a wide range of face to face examinations and are thus exposed to aerosols released by patient sneezing and coughing and are therefore particularly exposed to viral infection. Several studies have shown that HCWs, i.e., otorhinolaryngologists, anesthesiologists, and dentists, have been infected at higher rates than other HCWs [13-15]. In fact, these professionals comprised $12 \%$ of all physician deaths, leading to concern among HCWs in ENT $[10,16,17]$.

As the Danish healthcare system was not prepared for an epidemic of this nature, guidelines to reduce transmission to and among HCWs were initially absent at the department level. Through systematic tests and questionnaires, we traced asymptomatic, presymptomatic, and symptomatic HCWs. By tracking potential spreaders and identifying high risk procedures and work areas, the department enabled progressive development of infection control measures.

Our study had three aims: (1) To identify HCWs with a positive nasopharyngeal and oropharyngeal swab, (2) to evaluate self-reported COVID-19 symptoms by HCWs, and (3) to provide information to guide local transmission and infection control precautions at department level.

\section{Materials and methods}

We conducted a prospective observational cohort study at the Department of Otorhinolaryngology Head and Neck Surgery and Audiology, University Hospital of Copenhagen, Rigshospitalet-a tertiary referral center treating all
ENT-related conditions. The department has approximately 70,000 outpatient consultations every year, comprising head and neck cancer, benign ENT conditions, acute traumatology, as well as pediatric ENT conditions. In the study period, the ENT department had 361 employed HCWs comprising physicians, nurses, secretaries, porters, cleaners, audiologists, $\mathrm{PhD}$ and medical students. Participants were divided into professions (physicians, nurses, secretaries, porters, cleaners, and others) to follow disease spreading in the different groups.

Our study was conducted from March 27 to June 3, 2020 and included interval surveillance (baseline and three subsequent testing phases) of HCWs by sampling nasopharyngeal and oropharyngeal swab tests (in this study referred to as swab tests) determining SARS-CoV-2 RNA in upper airway mucosa and blood serology quantifying IgG specific for SARS-CoV-2 (Fig. 1). Test participants were asked to complete questionnaires concerning self-reported symptoms of COVID-19 at baseline, and at follow ups 1 and 2. Reported symptoms from the questionnaires were divided into three categories: (1) No symptoms and any symptoms, (2) no or mild symptoms, and (3) moderate or severe symptoms. The $2 \times 2$ contingency tables and correlations were analyzed using Pearson's chi-square test or Fischer's exact test when appropriate. For each day of testing (i.e., baseline and follow ups 1 and 2), the correlations were analyzed using Fischer's exact test. The data were analyzed using SPSS version 25 and $p$ values $<0.05$ were considered statistically significant.

\section{Data sampling}

\section{Nasopharyngeal and oropharyngeal swabs}

Nasopharyngeal and oropharyngeal swabs were performed by five ENT physicians to ensure swab procedure reproducibility. The exact same swab procedures were performed for all tests and followed international standards [18]. Oropharyngeal testing implied swabbing from the posterior pharyngeal wall and at least one tonsil in a continuous motion. Nasopharyngeal testing was performed unilaterally with the swab reaching rhinopharynx or at least inserted $2 / 3$ of the length and rotating at retraction. Both swabs were transported in the same medium (Copan UTM or similar) and analyzed at the Department of Clinical Microbiology, Rigshospitalet. SARS-CoV-2-RNA were detected either by the Cobas[ $\left[{ }^{\circledR}\right]$ SARS-CoV-2 real-time RTPCR test on the Cobas 6800 system (Roche, Switzerland) or using the RealStar® SARS-CoV-2 RT-PCR Kit (Altona, Germany). In brief: The nucleic acids in the patient sample were extracted together with an internal RNA control, using magnetic silica 


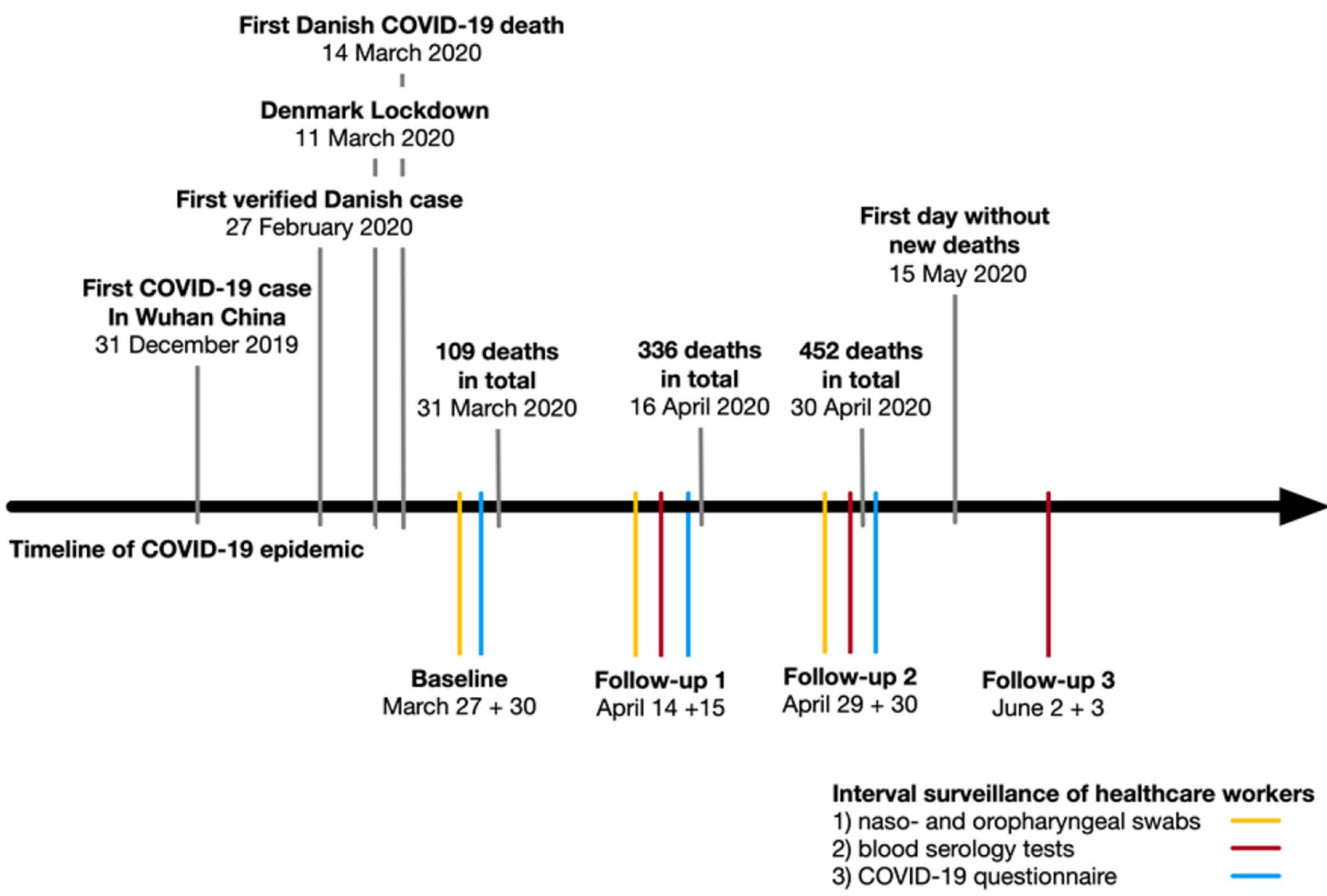

Fig. 1 Timeline showing project interventions during the development of COVID-19 epidemic in Denmark

particles, and transferred to a specific RT-PCR, targeting two separate gene segments.

\section{Blood serology}

Blood serology testing were carried out three times for quantification of SARS-CoV-2-IgM and SARS-CoV-2IgG. Blood samples were transported in two separate media and analyzed at the Department of Clinical Microbiology, Rigshospitalet. Analyses for SARS-CoV-2 IgG- and IgM antibodies were performed using the iFlash 1800 Chemiluminescence Immunoassay Analyzer (Shenzhen YHLO Biotech, Shenzhen, China) and YHLO SARS-CoV-2 IgG/ IgM tests kits.

Participants with SARS-CoV-2-IgG readout between 7 and $12 \mathrm{AU}$ were designated intermediate positive, while readouts above $12 \mathrm{AU}$ were categorized as positive. At the time of analyses, the manufacturer recommended using a cut off of $10 \mathrm{AE}$ for a positive readout. However, this recommendation has subsequently been changed to a cutoff value of 9 AU. In this study, we consider both the intermediate positive and the positive test result as positive.

\section{Questionnaire on self-reported symptoms}

The participants were asked to fill out questionnaires concerning self-reported symptoms of COVID-19. This took place at baseline and at follow ups 1 and 2. Follow ups 1, 2 , and 3 took place 2, 4, and 8 weeks after baseline, respectively. Test participants were asked to state the result of their last swab and their work e-mail as participant ID, if they had experienced fever in the previous week, and if they had any of 14 different symptoms on a four-point Likert scale (Table 1), ranging from no to severe symptoms. Included symptoms on the Likert scale were selected based on the available literature containing symptomatology of COVID$19[16,19]$, which was very limited in the initial phases of the pandemic.

\section{Department interventions}

During protocol writing for this study, there were neither comprehensive local, governmental, nor international guidelines to manage the SARS-CoV-2 epidemic in an ENT department. At an early stage of the epidemic, our 
Table 1 Overview of data collected from questionnaires

\begin{tabular}{|c|c|c|c|c|c|c|c|c|c|c|c|c|c|c|c|c|c|c|c|c|c|c|c|c|}
\hline \multirow{4}{*}{ Fever } & \multirow{2}{*}{\multicolumn{8}{|c|}{$\frac{\text { Baseline }}{2(2.0 \%)}$}} & \multirow{2}{*}{\multicolumn{8}{|c|}{$\frac{\text { Follow-up } 1}{1(0.5 \%)}$}} & \multicolumn{8}{|c|}{ Follow-up 2} \\
\hline & & & & & & & & & & & & & & & & & \multicolumn{8}{|c|}{$0(0 \%)$} \\
\hline & \multicolumn{2}{|c|}{$\begin{array}{l}\text { No } \\
\text { symp- } \\
\text { toms }\end{array}$} & \multicolumn{2}{|c|}{$\begin{array}{l}\text { Mild } \\
\text { symp- } \\
\text { toms }\end{array}$} & \multicolumn{2}{|c|}{$\begin{array}{l}\text { Mod- } \\
\text { erate } \\
\text { symp- } \\
\text { toms }\end{array}$} & \multicolumn{2}{|c|}{$\begin{array}{l}\text { Severe } \\
\text { symp- } \\
\text { toms }\end{array}$} & \multicolumn{2}{|c|}{$\begin{array}{l}\text { No symp- } \\
\text { toms }\end{array}$} & \multicolumn{2}{|c|}{$\begin{array}{l}\text { Mild } \\
\text { symp- } \\
\text { toms }\end{array}$} & \multicolumn{2}{|c|}{$\begin{array}{l}\text { Mod- } \\
\text { erate } \\
\text { symp- } \\
\text { toms }\end{array}$} & \multicolumn{2}{|c|}{$\begin{array}{l}\text { Severe } \\
\text { symp- } \\
\text { toms }\end{array}$} & \multicolumn{2}{|c|}{$\begin{array}{l}\text { No symp- } \\
\text { toms }\end{array}$} & \multicolumn{2}{|c|}{$\begin{array}{l}\text { Mild } \\
\text { symp- } \\
\text { toms }\end{array}$} & \multicolumn{2}{|c|}{$\begin{array}{l}\text { Mod- } \\
\text { erate } \\
\text { symp- } \\
\text { toms }\end{array}$} & \multicolumn{2}{|c|}{$\begin{array}{l}\text { Severe } \\
\text { symp- } \\
\text { toms }\end{array}$} \\
\hline & $n$ & $(\%)$ & $n$ & $(\%)$ & $n$ & $(\%)$ & $n$ & $(\%)$ & $n$ & $(\%)$ & $n$ & $(\%)$ & $n$ & $(\%)$ & $n$ & $(\%)$ & $n$ & $(\%)$ & $n$ & $(\%)$ & $n$ & $(\%)$ & $n$ & $(\%)$ \\
\hline Sore throat & 76 & 77.6 & 21 & 21.4 & 1 & 1 & 0 & 0 & 164 & 84.5 & 29 & 14.9 & 1 & 0.5 & 0 & 0 & 116 & 84.1 & 20 & 14.5 & 2 & 1.4 & 0 & 0 \\
\hline Sore body & 92 & 93.9 & 4 & 4.1 & 2 & 2 & 0 & 0 & 178 & 91.8 & 13 & 6.7 & 3 & 1.5 & 0 & 0 & 127 & 92 & 9 & 6.5 & 2 & 1.4 & 0 & 0 \\
\hline Rhinorrhea & 62 & 63.3 & 28 & 28.6 & 7 & 7.1 & 1 & 1 & 136 & 70.1 & 50 & 25.8 & 8 & 4.1 & 0 & 0 & 97 & 70.3 & 34 & 24.6 & 7 & 5.1 & 0 & 0 \\
\hline Nasal congestion & 75 & 76.5 & 20 & 20.4 & 1 & 1 & 2 & 2 & 158 & 81.4 & 30 & 15.5 & 5 & 2.6 & 0 & 0 & 109 & 79 & 24 & 17.4 & 5 & 3.6 & 0 & 0 \\
\hline Hyposmia & 94 & 95.9 & 4 & 4.1 & 0 & 0 & 0 & 0 & 180 & 92.8 & 12 & 6.2 & 1 & 0.5 & 1 & 0.5 & 126 & 91.3 & 10 & 7.2 & 1 & 0.7 & 1 & 0.7 \\
\hline Dysgeusia & 95 & 96.9 & 2 & 2 & 0 & 0 & 1 & 1 & 185 & 95.4 & 8 & 4.1 & 1 & 0.5 & 1 & 0.5 & 135 & 97.8 & 1 & 0.7 & 1 & 0.7 & 1 & 0.7 \\
\hline Sneezing & 61 & 62.2 & 34 & 34.7 & 2 & 2 & 1 & 1 & 114 & 58.8 & 75 & 38.7 & 5 & 2.6 & 0 & 0 & 89 & 64.5 & 40 & 29 & 9 & 6.5 & 0 & 0 \\
\hline Hoarseness & 92 & 93.9 & 4 & 4.1 & 1 & 1 & 1 & 1 & 185 & 95.4 & 9 & 4.6 & 0 & 0 & 0 & 0 & 132 & 95.7 & 6 & 4.3 & 0 & 0 & 0 & 0 \\
\hline Muscle ache & 92 & 93.9 & 5 & 5.1 & 1 & 1 & 0 & 0 & 175 & 90.2 & 14 & 7.2 & 5 & 2.6 & 0 & 0 & 125 & 90.6 & 10 & 7.2 & 3 & 2.2 & 0 & 0 \\
\hline Otalgia & 93 & 94.9 & 3 & 3.1 & 1 & 1 & 1 & 1 & 189 & 97.4 & 5 & 2.6 & 0 & 0 & 0 & 0 & 132 & 95.7 & 5 & 3.6 & 0 & 0 & 1 & 0.7 \\
\hline Headache & 68 & 69.4 & 22 & 22.4 & 5 & 5.1 & 3 & 3.1 & 144 & 74.2 & 34 & 17.5 & 16 & 8.2 & 0 & 0 & 94 & 68.1 & 34 & 24.6 & 7 & 5.1 & 3 & 2.2 \\
\hline Coughing & 79 & 80.6 & 15 & 15.3 & 2 & 2 & 2 & 2 & 152 & 78.4 & 34 & 17.5 & 8 & 4.1 & 0 & 0 & 114 & 82.6 & 24 & 17.4 & 0 & 0 & 0 & 0 \\
\hline Shortness of breath & 93 & 94.9 & 3 & 3.1 & 1 & 1 & 1 & 1 & 182 & 93.8 & 11 & 5.7 & 1 & 0.5 & 0 & 0 & 128 & 92.8 & 10 & 7.2 & 0 & 0 & 0 & 0 \\
\hline Shivering & 95 & 96.9 & 2 & 2 & 0 & 0 & 1 & 1 & 188 & 96.9 & 5 & 2.6 & 1 & 0.5 & 0 & 0 & 134 & 97.1 & 1 & 0.7 & 3 & 2.2 & 0 & 0 \\
\hline
\end{tabular}

department implemented local infection and transmission control measures according to our own risk assessment. From March12th, all referrals to the department were cancelled, with the exception of acute complications, traumas, and head and neck cancers. This led to an overall reduction in department activity across the in- and outpatient clinics as well as for the surgical activity. Doctors and nurses attending daily staff meetings maintained 2-m distancing. HCWs who tested positive was quarantined at home for 14 days and had to be asymptomatic and tested negative with swab tests before returning to the department. This was followingly revised to a 7-day quarantine, as it was shown that although COVID-19-positive individuals are positive for a long time period, the virus is assumed inactive following the symptomatic stage. Later, general nonevidence-based safety measures were published in international ENT journals and by European ENT organizations, such as the European Confederation of Oto-rhino-laryngology Societies (CEORL) and ENT UK, which provided inspiration to construct local guidelines in addition to those already made [20, 21].

At the beginning of the pandemic, the Danish Healthcare system and our department were challenged by low stock of personal protective equipment, especially FFP-3 (filtering facepiece), and swab tests. However, some personal protective equipment was available at the department. The department used disposable FFP-2 masks, gloves, and aprons when performing common ENT investigations and minor procedures, i.e., objective examination of the oral cavity, and only utilized disposable FFP-3, gloves, long-sleeved disposable gowns (covering arms and legs), and eye-protection in case of surgical airway management, tracheostomy cannula change, or respiratory tract suctioning. A regional storage system for protective equipment was set up to distribute the equipment, to manage stock, and to purchase new equipment, resulting in a steadily increasing access to equipment later in the pandemic. Nonphysician HCWs wore FFP-2 masks when in direct contact with patients suspected of COVID-19. Protective measures, such as plexiglass and additional hand sanitation stations, were set up in waiting areas and at secretary working stations.

\section{Outpatient clinic}

Non-COVID-19 areas and facilities in the ENT department were established. Patients suspected of COVID-19 were informed to wait outside the hospital and were clothed with face mask and escorted by a nurse to the designated COVID19 examination. The nurse ensured that the patient did not touch buttons in escalators or door handles. All nonessential high-risk ENT examinations, such as fiberlaryngoscopy in patients suspected of COVID-19 were reduced. In case of emergency airway evaluation or cancer investigation, a fiberoptic scope connected to a monitor was set up to keep a distance from the patient and minimize exposure to aerosols. 
Table 2 Overview of COVID19-positive participants and their profession

\begin{tabular}{llll}
\hline Professions & $\begin{array}{l}\text { No. associated with the } \\
\text { department }\end{array}$ & $\begin{array}{l}\text { Positive swab test (SARS- } \\
\text { CoV-2 RNA) }\end{array}$ & $\begin{array}{l}\text { Positive blood serol- } \\
\text { ogy (SARS-CoV-2 } \\
\text { IgG) }\end{array}$ \\
\hline Physicians & 80 & $4(5 \%)$ & $3(4 \%)$ \\
Nurses & 104 & $1(1 \%)$ & $2(2 \%)$ \\
Secretaries & 18 & $0(0 \%)$ & $1(6 \%)$ \\
Theatre personnel & 81 & $0(0 \%)$ & $4(5 \%)$ \\
Cleaning & 8 & $0(0 \%)$ & $0(0 \%)$ \\
Porters & 31 & $2(7 \%)$ & $4(13 \%)$ \\
Others & 25 & $0(0 \%)$ & $1(4 \%)$ \\
Totals & $\mathbf{3 4 7}$ & $\mathbf{7}$ & $\mathbf{1 5}$ \\
\hline
\end{tabular}

\section{Inpatient clinic}

Initially, only patients who were admitted with symptoms of upper respiratory tract infection or suspected of COVID-19 were swabbed and isolated in the ward until the swab test were analyzed. At a later stage when swab tests were readily available, all patients admitted were tested. All visits from relatives were suspended, except if admitted patients were children or patients suffering from terminal cancer. Examination of COVID-19 positive or suspected patients on ward round were performed in a separate examination room and followed by extensive cleaning using chlorine wipes following local guidelines. All staff in the in- and outpatient clinic wore personal protective equipment when in contact with patients suspected of COVID-19.

\section{Surgery}

Surgery on COVID-19 positive or suspected patients was performed in negative pressure surgical theatre and all personnel wore FFP-3 masks, face shields, and long-sleeved disposable fluid repellant surgical gowns (covering arms and legs). Removal and handling of personal protection equipment followed local guidelines for handling COVID-19 patients. All patients were tested with oro- and nasopharyngeal swabs before scheduled surgery. Surgical assistance to the hospitals designated COVID-19 intensive care unit were performed onsite and special full body garment with ENT headlights within the visor were purchased for this task. Our department mostly assisted with elective tracheostomy in intubated COVID-19 patients.

\section{Ethical considerations}

All participants participated voluntarily and signed informed consent before entering the study. All participants were informed that their participation could be withdrawn instantaneously if opted for. All data were stored confidentially and only the primary researcher had access to the data.
The study protocol was published on Clinical Trials no: NCT04356560, and approved by the Danish Data Protection agency (DT P-2020-353).

\section{Results}

A total of 347 out of 361 (96\%) HCWs were tested at least once during the four test rounds, resulting in a total of 693 swab tests and 664 blood tests. At baseline, 210 individuals participated. The numbers of participants at the follow ups were 246,241 , and 174 at follow ups 1,2 , and 3, respectively. A total of 97 (40\%), 191 (79\%), and 143 (81\%) participants replied to the questionnaire at baseline and follow ups 1 and 2, respectively. The distribution of professions is shown in Table 2. A total of four physicians, one nurse and two porters were tested positive with nasopharyngeal and oropharyngeal swab tests across all test intervals.

The highest incidence was seen at follow-up 1, where six HCWs had a positive swab test. Of these, none could be tracked to have had specific work interactions with each other, except for two porters who shared office. At baseline, one $\mathrm{HCW}$ (porter) had a positive swab test. At follow-up 1 , he was retested as positive, and an additional porter was tested positive. None of the 29 other porters who used the office during shifts were tested positive in the study period. The second HCW with a positive test had been working with different procedures and in different areas in the department and no patterns or relations were identified. At follow-up 2, one new HCW tested positive. Apart from the two porters, there were no signs of transmission within the department. Table 3 presents the data from swab and blood serology testing. A total of fifteen participants developed antibodies during the study period-eight of which tested positive twice. Twelve participants developed antibodies, but did not have a positive swab test at any point of time, and three participants came out as intermediate. No participants were tested positive in follow-up 3. In follow-up 3, only six HCWs participated out of the 19 who had previously been tested positive 
Table 3 Participants tested positive either by swab tests, blood tests or both at baseline and 3 follow ups. ' - ' for negative test, ' + ' for positive test, and ' $\nabla$ ' if no test were made

\begin{tabular}{|c|c|c|c|c|c|c|}
\hline & \multirow{2}{*}{$\begin{array}{l}\text { Baseline } \\
\text { Swab }\end{array}$} & \multicolumn{2}{|c|}{ Follow-up 1} & \multicolumn{2}{|c|}{ Follow-up 2} & \multirow{2}{*}{$\begin{array}{l}\text { Follow-up } 3 \\
\text { Blood }\end{array}$} \\
\hline & & Swab & Blood & Swab & Blood & \\
\hline Participant 1 & - & - & + & $\nabla$ & $\nabla$ & $\nabla$ \\
\hline Participant 2 & - & - & + & - & + & - \\
\hline Participant 3 & $\nabla$ & - & + & $\nabla$ & $\nabla$ & - \\
\hline Participant 4 & $\nabla$ & - & + & - & + & $\nabla$ \\
\hline Participant 5 & - & - & + & - & + & $\nabla$ \\
\hline Participant 6 & $\nabla$ & + & + & + & + & $\nabla$ \\
\hline Participant 7 & - & - & + & - & + & $\nabla$ \\
\hline Participant 8 & $\nabla$ & + & + & - & + & $\nabla$ \\
\hline Participant 9 & - & $\nabla$ & $\nabla$ & - & + & $\nabla$ \\
\hline Participant 10 & - & - & + & - & + & $\nabla$ \\
\hline Participant 11 & $\nabla$ & $\nabla$ & - & $\nabla$ & + & $\nabla$ \\
\hline Participant 12 & $\nabla$ & $\nabla$ & $\nabla$ & - & + & $\mathrm{v}$ \\
\hline Participant 13 & $\nabla$ & $\nabla$ & $\nabla$ & - & + & $\nabla$ \\
\hline Participant 14 & + & + & + & $\nabla$ & + & $\nabla$ \\
\hline Participant 15 & $\nabla$ & - & + & $\nabla$ & $\nabla$ & $\nabla$ \\
\hline Participant 16 & - & + & - & - & - & - \\
\hline Participant 17 & $\nabla$ & + & - & - & - & - \\
\hline Participant 18 & - & $\nabla$ & $\nabla$ & + & - & - \\
\hline Participant 19 & $\nabla$ & + & - & - & - & - \\
\hline Total positives: & 1 & 6 & 11 & 2 & 12 & 0 \\
\hline
\end{tabular}

either by swab or blood test, and all six had a negative blood test. The remaining 13 of the $19 \mathrm{HCW}$ s blood tests were either not collected or lost. Two participants reported having fever within the previous week at baseline, which declined to one participant at follow-up 1 and none at follow-up 2 (Table 3), yet none of these were tested positive in either swab or blood tests. The most frequent reported severe symptom was headache $(3[3,1 \%])$ at baseline and at followup 2. No significant difference was found when comparing the participants having no symptoms to participants having any symptoms at any of the test dates $(p=0.221)$. No participants were tested positive at baseline. At follow-up 1, six participants had positive swab tests, and one reported moderate to severe symptoms (sore throat, $p=0.557$ ). Eleven participants had positive blood tests, of which two reported moderate to severe symptoms $(p=0.641)$. Participant 4 reported severe hyposmia and moderate muscle ache, dysguesi, and sore body. Participant 3 reported moderate coughing. At follow-up 2, two participants had positive swab tests and one participant reported moderate to severe symptoms (muscle ache and headache, $p=0.340$ ). Nine participants had positive blood tests, of which three reported moderate to severe symptoms $(p=0.366)$. Participant 4 reported severe hyposmia and moderate dysguesi, Participant 10 reported moderate nasal congestion and sneezing, and Participant 14 reported moderate sneezing. Four times a swab or blood test positive participant reported a severe symptom: At baseline, Participant 10 reported nasal congestion; at follow-up 1,
Participant 4 reported hyposmia; at follow-up 2, Participant 4 reported hyposmia, and Participant 19 reported headache. Participant 19 reported severe headache at follow-up 2, but was swab test positive in follow-up 1. No correlations were found between symptoms and the performed tests.

\section{Discussion}

We present novel data from testing $361 \mathrm{HCW}$ s employed at a tertiary ENT department during the COVID-19 pandemic. To the best of our knowledge, the data represent the only department in Denmark that has tested staff systematically since the start of the epidemic, including infectious medicine and COVID intensive care units. With thorough and repeated testing during a period of approximately 2.5 months, our study data show a very low infection rate. Only 7 and 15 participants were tested positive with swab tests and blood samples, respectively. In general, participants reported very few symptoms and few participants reported the same symptom at a later test day. Only one participant, Participant 4 reported a severe symptom (hyposmia) twice (at follow ups 1 and 2). No significant correlations between positive tests and self-reported symptoms were found.

In parallel to this study, we conducted a study aiming to detect COVID-19-positive patients who were referred to our department with symptoms of acute infection, such as peritonsillar abscesses etc. In that study, Andersen et al. 
found one of 89 urgently referred patients with symptoms of COVID-19, indicating that the primary healthcare system in the hospitals catchment area was well-functioning and successful in detecting COVID-19-positive patients before referral (unpublished data). This might explain why we did not see as many infected HCWs as previous studies have found [13]. Especially in China [17], Italy [22] and the United Kingdom [23], reported high numbers of infected HCWs, and reports from Italy and United Kingdom states that HCWs are continously infected in high numbers. Here, extreme measures have been made to protect HCWs. In the UK, physicians still consult fewer patients and wear full protective gear at all consultations [24].

At follow-up 3, no participants were tested positive. The total number of tests decreased from 241 to 174 between follow ups 2 and 3. Six participants out of the 19 who had previously been tested positive either by swab or blood test, were tested negative. It is the authors impression that HCWs at the department supported the regular tests despite discomfort from especially the nasopharyngeal swab test. The declining number of tests through follow-up was mainly due to logistic failure and loss of tests. During the pandemic, the national test capacity was enlarged multiple times leading to an overburdening of the test facilities and logistics.

In contrast to the initial hypothesis, we did not see a high number of infected HCWs, even though they were considered a population at high risk. There are several possible explanations. First, the low prevalence of infection in Denmark in combination with the quick lock down from the Danish government, contained the virus from spreading, not reaching our department. Second, all patients with suspected COVID-19 infection were initially assessed in test centers outside the hospital. Here, an oropharyngeal swab test was performed. The capacity of the test centers became insufficient along the way, which prompted initiation of our own test protocol, testing all incoming patients in our outpatient clinic. Third, the infected participants did not transmit the disease to his or her coworkers, because the quarantine measures that were arranged contained the virus. Fourth, reduced department activity could be an important reason for reduced risk of HCWs infection.

A limitation of the present study was the difficulties regarding gathering of the data in the department in the initial phase of the epidemic. We intended to include all earlier enrolled participants, but it was difficult to conduct a follow-up study during opening hours of the clinic. Some of the participants included early in the study, did not participate later due to practicalities. Either they were working elsewhere in the clinic or send on leave on the test days. We tried to accommodate this limitation by having consecutive test days. In a similar study to ours, Paderno et al. reported low rates of infection among healthcare workers at a nonCOVID-19 otorhinolaryngology department due to the use of adequate PPE [25]. ENT UKs latest recommendations suggest that upper airway endoscopy is merely a potential aerosol generating procedure, and that the majority of endoscopies will not generate aerosol or droplets, hereby downgrading the risk of infection. This corresponds to our findings: although routine ENT examinations, nasal endoscopic procedures, and other airway procedures may induce release of aerosols, in the outpatient clinic and during surgery, we did not find a high number of infected HCWs. With great care and focus on correct use of personal protective gear, we may lower the risk for ENT HCWs, making it paramount to have access to enough protective gear at an expected second wave of COVID-19 in late 2020.

\section{Conclusion}

Adherence to the surveillance program was high among the HCWs. The incidence among HCW at a high-volume ENT department was low and may reflect effective local transmission and infection control precautions, as well as a low infectious burden in the Danish society. The developed work routines may constitute a basis of preparedness and response measures at a possible second wave of the epidemic in late 2020 .

\section{Key points}

Question: How does SARS-CoV-2 spread among otorhinolaryngology healthcare workers (HCWs) in a hospital setting, and can ongoing surveillance identify cases, pathways, and high-risk areas within the department?

Findings: Through the first wave of the epidemic, presymptomatic and asymptomatic HCWs with SARS-CoV-2 were identified in the surveillance program. Transmission and overall infection rates were kept low.

Meaning: Early identification of infected HCWs may prevent outbreaks within a hospital department.

Author contributions Study design: Ramon Gordon Jensen, Kasper Aanæs, Hani Ibrahim Channir; Drafting of the manuscript Kasper Møller Boje Rasmussen; Revision of the manuscript: All authors; Final approval: All authors; Final agreement: All authors.

Funding The authors report no funding,

\section{Compliance with ethical standards}

Conflict of interest The authors report no conflicts of interest to disclose. 
Ethics approval An application for The Scientific Ethics Committee of the Capitol Region were sent before the beginning of the project (H-20026456), but the project did not need to be approved by the Scientific Ethics Committee.

Consent to participate All participants signed informed consents before entering the study.

Consent for publication Informed consent for publication has been obtained all authors.

Availability of data and material All data are available for the publisher. The corresponding author can be contacted regarding this.

\section{References}

1. John Hopkins University (2020) Coronavirus Resource Center [Internet]. [cited 2020 Jun 8]. Available from: https://coronaviru s.jhu.edu/map.html

2. Roser M, Ritchie H, Ortiz-Ospina E, Hasell J (2020) Coronavirus Pandemic (COVID-19). Published online at OurWorldInData.org. Retrieved from: https://ourworldindata.org/coronavirus

3. Danish Patient Safety Authority. Første dansker er bekræftet smittet med COVID-19 (ny coronavirus) [Internet]. 2020. Available from: https://stps.dk/da/nyheder/2020/foerste-dansker-erbekraeftet-smittet-med-covid-19-ny-coronavirus/

4. Statens Serum Institut. COVID-19 overvågningsrapport [Internet]. [cited 2020 Jun 24]. Available from: https://www.sst.dk/da/coron a/tal-og-overvaagning

5. Zou L, Ruan F, Huang M, Liang L, Huang H, Hong Z et al (2020) SARS-CoV-2 viral load in upper respiratory specimens of infected patients. N Engl J Med 382:1177-1179

6. Van Doremalen N, Bushmaker T, Morris DH, Holbrook MG, Gamble A, Williamson BN et al (2020) Aerosol and surface stability of SARS-CoV-2 as compared with SARS-CoV-1. N Engl J Med 382:1564-1567

7. Li Q, Guan X, Wu P, Wang X, Zhou L, Tong Y et al (2020) Early transmission dynamics in Wuhan, China, of novel coronavirusinfected pneumonia. N Engl J Med 382(13):1199-1207

8. Xiang F, Wang X, He X, Peng Z, Yang B, Zhang J et al (2020) Antibody detection and dynamic characteristics in patients with COVID-19. Clin Infect Dis 71:1930-1934

9. To KKW, Tsang OTY, Leung WS, Tam AR, Wu TC, Lung DC et al (2020) Temporal profiles of viral load in posterior oropharyngeal saliva samples and serum antibody responses during infection by SARS-CoV-2: an observational cohort study. Lancet Infect Dis 20(5):565-74. https://doi.org/10.1016/S1473-3099(20)30196-1

10. Young BE, Ong SWX, Kalimuddin S, Low JG, Tan SY, Loh J et al (2020) Epidemiologic features and clinical course of patients infected with SARS-CoV-2 in Singapore. JAMA J Am Med Assoc 323(15):1488-1494

11. Gudbjartsson DF, Helgason A, Jonsson H, Magnusson OT, Melsted P, Norddahl GL et al (2020) Spread of SARS-CoV-2 in the Icelandic population. N Engl J Med 382(24):2302-2315
12. Rothe C, Schunk M, Sothmann P, Bretzel G, Froeschl G, Wallrauch C et al (2020) Transmission of 2019-NCOV infection from an asymptomatic contact in Germany. N Engl J Med 382(10):970-971

13. Ing EB, Xu QA, Salimi A, Torun N (2020) Physician deaths from corona virus (COVID-19) disease. Occup Med (Chic Ill) 70:370-374

14. Chan JYK, Tsang RKY, Yeung KW, Abdullah V, Ku P, Wong EWY et al (2020) There is no routine head and neck exam during the COVID-19 pandemic. Head Neck 42(6):1235-1239

15. Mick P, Murphy R (2020) Aerosol-generating otolaryngology procedures and the need for enhanced PPE during the COVID-19 pandemic: A literature review. J Otolaryngol Head Neck Surg 49(1):1-10

16. Wang D, Hu B, Hu C, Zhu F, Liu X, Zhang J et al (2020) Clinical characteristics of 138 hospitalized patients with 2019 novel coronavirus-infected pneumonia in Wuhan, China. JAMA J Am Med Assoc 323(11):1061-1069

17. Cui C, Yao Q, Zhang D, Zhao Y, Zhang K, Nisenbaum E et al (2020) Approaching otolaryngology patients during the COVID19 Pandemic. Otolaryngol Head Neck Surg 163:121-131

18. Todsen $T$ (2020) Nasopharyngeal and oropharyngeal swab test for COVID-19 [Internet]. Denmark. Available from: https://vimeo .com/400207098

19. Krajewska J, Krajewski W, Zub K, Zatoński T (2020) COVID19 in otolaryngologist practice: a review of current knowledge. Eur Arch Oto-Rhino-Laryngol 277(7):1885-97. https://doi. org/10.1007/s00405-020-05968-y

20. Ter CVW, Khoo MLC, Lee SF, Lai YC, Chin NM (2004) Infection control measures for operative procedures in Severe Acute Respiratory Syndrome-related patients. Anesthesiology 100(6):1394-1398

21. ENT UK. Ten key guidance points: Aerosol Generating Procedures ( AGPs ) within the ENT clinic [Internet]. [cited 2020 Jun 8]. Available from: https://www.entuk.org/ten-key-guidance-point s-aerosol-generating-procedures-agps-within-ent-clinic

22. Lapolla P, Mingoli A, Lee R (2020) Deaths from COVID-19 in healthcare workers in Italy - What can we learn? Infect Control Hosp Epidemiol. https://doi.org/10.1017/ice.2020.241

23. Hunter E, Price DA, Murphy E, van der Loeff IS, Baker KF, Lendrem D et al (2020) First experience of COVID-19 screening of health-care workers in England. Lancet 395(10234):e77-8. Available from: https://linkinghub.elsevier.com/retrieve/pii/S0140 673620309703

24. ENT UK (2020) Guidance for ENT during the COVID-19 pandemic You are here. Available from: https://www.entuk.org/guida nce-ent-during-covid-19-pandemic

25. Paderno A, Fior M, Berretti G, Schreiber A, Grammatica A, Mattavelli D, et al (2020) SARS-CoV-2 Infection in Health Care Workers: Cross-sectional Analysis of an Otolaryngology Unit. Otolaryngol - Head Neck Surg (United States). 1-2

Publisher's Note Springer Nature remains neutral with regard to jurisdictional claims in published maps and institutional affiliations. 